CNS Spectrums (2014), 19, 391-402. C Cambridge University Press 2014. The online version of this article is published within an Open Access environment subject to the conditions of the Creative Commons Attribution-NonCommercial-ShareAlike licence <http://creativecommons.org/licenses/by-nc-sa/3.0/ > . The written permission of Cambridge University Press must be obtained for commercial re-use. doi: $10.1017 /$ S1092852914000157

\title{
Clozapine: an effective treatment for seriously violent and psychopathic men with antisocial personality disorder in a UK high-security hospital
}

\author{
Darcy Brown, ${ }^{\prime}$ Fintan Larkin, ${ }^{2}$ Samrat Sengupta,${ }^{2}$ Jose L. Romero-Ureclay, ${ }^{2}$ \\ Callum C. Ross, ${ }^{2}$ Nitin Gupta, ${ }^{3}$ Morris Vinestock, ${ }^{2}$ and Mrigendra Das ${ }^{2 *}$
}

\footnotetext{
${ }^{1}$ The School of Medicine and Dentistry, University of Aberdeen, Aberdeen, UK

${ }^{2}$ Broadmoor Hospital, West London Mental Health Trust, Berkshire, UK

${ }^{3}$ Department of Psychiatry, Government Medical College and Hospital, Chandigarh, India
}

Objective. A number of studies have demonstrated the anti-aggressive properties of clozapine in schizophrenia and its positive effect in borderline personality disorder. There is no published literature on the treatment of antisocial personality disorder (ASPD) with clozapine. We present a case series of 7 patients with primary ASPD and high psychopathic traits treated with clozapine, having a significant history of serious violence and currently detained in a UK based high-security hospital.

Methods. A retrospective review of case notes was carried out to formulate Clinical Global Impression (CGI) scores and record incidents of violence and aggression. Effect on specific symptom domains (cognitive-perceptual, impulsive-behavioural dyscontrol, affective dysregulation) was also noted. Metabolic parameters and serum clozapine levels were also sampled.

Results. All 7 patients showed significant improvement on clozapine. It was shown to benefit all symptom domains, especially impulsive behavioral dyscontrol and anger. The number of violent incidents committed by 6 of the 7 patients reduced significantly, and all patients' risk of violence reduced. Clozapine serum levels for 6 of the 7 patients were in the range $150-350 \mathrm{ng} / \mathrm{mL}$.

Conclusion. Clozapine is of benefit in reducing the clinical severity of ASPD. It improved all symptom domains, especially impulsive-behavioral dyscontrol and anger, and reduced levels of aggression and violence, especially at lower doses (serum levels $<350 \mathrm{ng} / \mathrm{m}$ ). To our knowledge, this is the first account of clozapine treatment in patients with ASPD and high psychopathy.

Received 6 January 2014; Accepted 7 February 2014; First published online 3 April 2014

Key words: Antipsychotic, antisocial, clozapine, personality disorder, psychopath, violence.

\section{Introduction}

In recent years, the evidence base to support the use of pharmacotherapy in personality disorders has grown.

\footnotetext{
*Address for correspondence: Mrigendra Das, Broadmoor Hospital, Crowthorne, Berkshire, RG45 7EG, UK.

(Email: mrigendra.das@wlmht.nhs.uk)

We wish to thank John Wakelam and Stephen Heslop (pharmacists at Broadmoor Hospital) and Ottilie Sedgwick (research psychologist at Broadmoor Hospital) for their assistance in accessing records.
}

A number of recent systematic reviews examining this issue concluded that, of the available treatments, mood stabilizers and atypical antipsychotics demonstrated the most clinical benefit. ${ }^{1-3}$

A number of atypical antipsychotics, including quetiapine, ${ }^{4-6}$ aripiprazole,${ }^{7}$ and paliperidone, ${ }^{8}$ have been found to be effective in improving the clinical symptoms of borderline personality disorder (BPD). ${ }^{9}$ In addition to displaying a positive effect in $\mathrm{BPD},{ }^{10-14}$ olanzapine also reduces symptoms of psychosis and 
depression in schizotypal personality disorder. ${ }^{15}$ Similarly, low-dose risperidone reduces the severity of schizotypal ${ }^{16}$ and borderline ${ }^{17}$ personality disorders.

Of the atypical antipsychotics, clozapine has shown promising results in the treatment of personality disorder. Clozapine, an atypical antipsychotic with a wide-ranging receptor profile, ${ }^{18}$ is used in the treatment of schizophrenia. Studies have shown that it is of particular benefit in treatment-resistant schizophrenia, ${ }^{19}$ with response rates between $30 \%$ and $60 \% .^{20-22}$ Clozapine was found to significantly reduce incidents of self-harm and aggression in a case series of 7 female patients with severe BPD. ${ }^{23}$ Other studies, including a case report, ${ }^{24} 2$ case series, ${ }^{25,26}$ and a prospective open-label study involving 15 patients, ${ }^{27}$ replicated similarly positive results.

Clozapine is also widely known for its anti-aggressive effects, ${ }^{28,29}$ which have most commonly been demonstrated among schizophrenia patients. ${ }^{30-35}$ In a randomized control trial comparing clozapine, olanzapine, and haloperidol, all 3 drugs showed similar antipsychotic effects; however, clozapine showed a significantly better effect in reducing violent incidents, thus indicating its specific anti-aggressive effects. ${ }^{36}$

As clozapine has been shown to be of benefit in certain subtypes of personality disorder and also in reducing aggression in schizophrenia, it is reasonable to hypothesize that it may improve the clinical severity and also reduce aggression and violence in patients with antisocial personality disorder. There is currently limited research in this area.

We present a case series of 7 men with a primary diagnosis of antisocial personality disorder (ASPD) and who also scored high on psychopathy (as assessed by a validated psychopathy checklist). ${ }^{37,38}$ All patients had a significant history of serious violence and were commenced on clozapine treatment while being cared for in a high-security hospital.

\section{Method}

All patients reported in this article were inpatients at Broadmoor Hospital (a high-security hospital). There are three high-security hospitals in England and Wales with 797 beds, caring for a population of 56 million. High-security hospitals treat patients who have committed serious offences, have severe psychiatric conditions, and therefore pose the highest level of risk to others such that they cannot be managed in other security settings. Typically, the most common diagnosis is schizophrenia, followed by personality disorder. Patients are detained under the Mental Health Act and include patients transferred from less security hospital units or prisons, or those who receive a hospital treatment order at sentencing from court. The hospital has wards that are distinguished by the level of dependency or risk that the patient poses. This ranges from Intensive Care or High Dependency to rehabilitation wards from where patients are discharged. Patients are discharged to less security hospitals or repatriated to prison once their treatment is complete.

At the time of writing of this case series, 6 ASPD patients were receiving clozapine in the hospital. Through examining pharmacy records, 1 further patient was noted to have received a previous discontinued trial of clozapine, and he was also included in this case-series study. All the patients were able to provide informed consent for this retrospective case series. Patients were initiated on clozapine as per the hospital's titration protocol while they were inpatients on a high-dependency ward in the hospital. Doses of clozapine for each patient were recorded, and any changes in these doses and any concurrent medications were noted.

The Clinical Global Impression Scale (CGI) was used to assess the clinical severity and post-intervention changes of patient symptoms. ${ }^{39}$ CGI is a commonly used scale for measuring the effect of pharmacological intervention in various studies on personality disorders. ${ }^{40,41}$ Scores were formulated retrospectively by the authors (MD, DB) using clinical information examining the patients' illness severity before and after commencement of clozapine treatment. Outcome variables (as described by Soloff ${ }^{42}$ and Ingenhoven et $\mathrm{al}^{1}$ ) were also derived, this time by the treating psychiatrist using the following symptom domains: cognitive-perceptual symptoms, impulsivebehavioral dyscontrol, and affective dysregulation. The treating psychiatrists were asked to rate patients' response, following clozapine treatment, in these domains as follows: worsened, remained the same, some improvement, or much improvement. The cognitiveperceptual domain included feelings of paranoia, suspiciousness, referential thinking, depersonalization, illusions, and hallucination-like symptoms; impulsive -behavioral dyscontrol described symptoms such as impulsive aggression, self-harm, promiscuity, excessive spending, and substance abuse; the affective dysregulation domain illustrated abnormal emotional responses such as mood lability, rejection sensitivity, outbursts of temper, low mood, and inappropriateness of intense anger. This final domain had 4 subdomains: low mood, anxiety, anger, and mood lability.

Psychopathy was assessed by either the Revised Psychopathy Checklist (PCL-R), ${ }^{37}$ which is a validated tool assessing psychopathy, or the Psychopathy ChecklistScreening Version (PCL-SV). ${ }^{38}$ Scores of 28 or more out of a possible score of 40 on PCL-R or a score of 16 or more out of a possible score of 24 on PCL-SV were considered indicative of psychopathy.

The case notes were also reviewed for episodes of seclusion, violent incidents, and episodes of self-harm and positive factors such as engagement in occupational 
therapy (OT), vocational activities, and psychological therapies. Formal risk assessments (HCR-20) ${ }^{43}$ and the hospital's own high risk assessment were reviewed to gauge change in risk status. Planned moves to lower or higher dependency wards were also noted. Clinical reports were examined for details of patients' index offences. All of this information was used to measure risk of aggression prior to and after commencement of clozapine.

We examined metabolic parameters, where these were available, using the latest value prior to and after initiation of clozapine, including BMI (body mass index), total cholesterol:high density lipid (HDL) ratio, and blood glucose levels.

\section{Results}

None of the patients had a comorbid diagnosis of schizophrenia or schizoaffective disorder. They also did not have any history of learning disability, brain injury, epilepsy, or concurrent substance abuse. Patients had an average age of 33.3 years. All patients were diagnosed by the treating consultant psychiatrist with primary ASPD. They also had other personality disorder traits (see Table 1). All clinical diagnoses and exclusions were made by the treating consultant psychiatrist using International Statistical Classification of Diseases and Related Health Problems, 10th revision (ICD-10) ${ }^{44}$ and Diagnostic and Statistical Manual of Mental Disorders, 4th edition (DSM-IV) ${ }^{45}$ criteria. Patients received a mean clozapine dosage of $171 \mathrm{mg}$ per day (range $100 \mathrm{mg}$ to $325 \mathrm{mg}$ per day) for at least 7 weeks (range 7 to 67 weeks, median 14 weeks).

\section{Symptom improvement}

Of the 7 patients, 1 had a CGI score that displayed "vast improvement" (reduced CGI by 4 points), 1 showed "major improvement" (reduced CGI by 3 points), and all other patients $(\mathrm{N}=5)$ displayed "significant improvement" (reduced CGI by 2 points). The severity of illness decreased significantly for all patients (see Table 2).

With regard to improvement in specific symptom domains, 6 of the 7 patients showed improvement in the cognitive-perceptual domain. All of the patients showed improvement in impulsive-behavioral dyscontrol. All patients showed improvement in some aspect of affective dysregulation; specifically, 4 showed improved symptoms of low mood, 5 in anxiety, all demonstrated improved anger control, and 6 of the 7 improved mood lability.

\section{Clozapine and nor-clozapine serum levels, concurrent medication}

Data were available for clozapine and nor-clozapine levels for 6 of the 7 patients. Levels were not available for one patient (Patient F), as he was on clozapine for 7 weeks only, and subsequently it was discontinued. Serum clozapine level results were as follows: 150, 160, $170,230,270$, and $350 \mathrm{ng} / \mathrm{mL}$. Concurrent psychotropic medication was recorded (see Table 2). None of the patients was started on any antipsychotic or other psychotropic medication concurrently after the initiation of clozapine.

\section{PCL-SV and PCL-R scores}

All patients scored highly on psychopathy as assessed by the PCL-SV (all scored 19 or above out of 24 ; mean: 19.6; range: 19-21). One patient had an additional PCL-R assessment and scored 28 out of 40 . These tests were administered by a trained psychologist or doctor.

\section{Improvement in aggression and violence}

All patients' risk of violence and aggression to others reduced following treatment with clozapine, as quantified by formal risk assessment changes and staff opinions recorded in the weekly records. In all cases, this risk reduction was associated with clinical improvement in symptoms and positive engagement with OT and psychological therapies. In 3 of the 7 patients, their risk reduced sufficiently to merit a move to a lower dependency ward or transfer to a medium-security unit. None of the patients had to be moved to a higher dependency ward following commencement on clozapine.

Incidents of violence logged in the hospital's incident reporting system were assessed in the 90 days before clozapine was initiated and in the most recent 90 days on clozapine at the time of the writing of this report. It will be pertinent to mention here that in cases where clozapine was started less than 90 days after admission to the hospital, potential incidents may have been missed, as we did not have access to other hospitals' or prison service records. Post-clozapine initiation, no incidents were missed for any patient, as all hospital records were available. Incidents were divided into the following subgroups: verbal aggression, aggression toward property, aggression toward others (physical), and self-harm.

Six of the 7 patients showed a reduction in their number of total violent incidents, with 4 of the 6 demonstrating a $100 \%$ reduction (see Table 3 and Figure 1). The remaining patient (Patient C: see Case Reports) did not have any recorded incidents before or after clozapine was initiated, but reported a diminished preoccupation with violent fantasies.

\section{Metabolic Parameters (see Table 4) and side effects}

Four patients' body mass index (BMI) increased and 3 decreased over the treatment time period. The mean 


\begin{tabular}{|c|c|c|c|c|c|c|c|}
\hline Patient & Age & Diagnosis & PCL-SV score & $\begin{array}{l}\text { Current duration in } \\
\text { HSH (months) }\end{array}$ & $\begin{array}{l}\text { Previous time as } \\
\text { inpatient (months) }\end{array}$ & Descriptors of aggression, self-harm, and details of index offense & Previous medications tried \\
\hline A & $25-29$ & $\begin{array}{l}\text { Antisocial personality disorder with } \\
\text { paranoid traits }\end{array}$ & $21 / 24$ & 34 & 60 & $\begin{array}{l}\text { Numerous assaults, interpersonal violence, violence toward animals. } \\
\text { Cuts on his hands, banging arms and knuckles. } \\
\text { Index offense: attempted murder of close relative. }\end{array}$ & $\begin{array}{l}\text { Clozapine, quetiapine, mirtazepine, citalopram, } \\
\text { venlafaxine }\end{array}$ \\
\hline B & $30-34$ & $\begin{array}{l}\text { Antisocial-schizoid personality disorder } \\
\text { with borderline, paranoid, and } \\
\text { narcissistic traits }\end{array}$ & $21 / 24$ & 4 & 0 & $\begin{array}{l}\text { Numerous assaults, arson, sexual assault, attempted murder. } \\
\text { History of overdose and cutting his arms. } \\
\text { Index offense: murder of fellow prisoner by strangulation followed by } \\
\text { attempt at decapitation. }\end{array}$ & Amitriptyline, promethzaine \\
\hline c & $30-34$ & $\begin{array}{l}\text { Antisocial personality disorder with } \\
\text { borderline traits }\end{array}$ & 19/24 & 11 & 0 & $\begin{array}{l}\text { Numerous assaults, weapon possession, actual bodily harm, and } \\
\text { has frequent fantasies about violence. } \\
\text { No history of self-harm. } \\
\text { Index offense: extremely violent murder. }\end{array}$ & Olanzapine \\
\hline D & $25-29$ & $\begin{array}{l}\text { Antisocial-paranoid personality } \\
\text { disorder }\end{array}$ & $19 / 24$ & 28 & 6 & $\begin{array}{l}\text { Numerous assaults, violence toward animals, strangulation, and } \\
\text { stabbing. } \\
\text { No history of self-harm. } \\
\text { Index offense: robbery and assault with intention to cause grievous } \\
\text { bodily harm. }\end{array}$ & $\begin{array}{l}\text { Citalopram, fluoxetine, quetiapine, sertraline, } \\
\text { mianserin }\end{array}$ \\
\hline $\mathrm{E}$ & $50-54$ & $\begin{array}{l}\text { Antisocial personality disorder with } \\
\text { borderline traits }\end{array}$ & $19 / 24^{*}$ & 18 & 48 & $\begin{array}{l}\text { Multiple sexual assaults, violent assaults, theft. } \\
\text { Self-neglect, refusal to eat, self-mutilation. } \\
\text { Index offense: Three counts of rape. }\end{array}$ & Diazepam \\
\hline $\mathrm{F}$ & $30-34$ & $\begin{array}{l}\text { Antisocial personality disorder with } \\
\text { borderline and paranoid traits }\end{array}$ & $19 / 24$ & 78 & 72 & $\begin{array}{l}\text { Numerous assaults to staff and patients, assault on family } \\
\text { members, stabbing, use of weapons. } \\
\text { History of cutting himself, attempted to hang himself. } \\
\text { Index offense: Actual bodily harm, possession of a weapon, } \\
\text { and affray. }\end{array}$ & $\begin{array}{l}\text { Aripiprazole, citalopram, clonazapam, diazepam, } \\
\text { lithium carbonate, mirtazepine, palperidone, } \\
\text { promethazine, risperidone }\end{array}$ \\
\hline G & $30-34$ & $\begin{array}{l}\text { Antisocial-paranoid personality } \\
\text { disorder with borderline traits. }\end{array}$ & $19 / 24$ & 16 & 0 & $\begin{array}{l}\text { Numerous assaults and interpersonal violence. History of creating } \\
\text { and using weapons. } \\
\text { No history of self-harm. } \\
\text { Index offense: burglary and assaulted shop-keeper with a knife. }\end{array}$ & Aripiprazole, diazepam, zopiclone \\
\hline
\end{tabular}

PCL-SV: Psychopathy Checklist-Screening Version. ${ }^{38}$ A score of $16 / 24$ or greater indicates psychopathy; HSH: High-security hospital.

${ }^{*}$ This patient had an additional PCL-R (Hare Psychopathy Checklist-Revised). ${ }^{37}$ This patient scored 28/40, which indicates psychopathy. 
TABLE 2. Treatment details and results

\begin{tabular}{|c|c|c|c|c|c|c|c|c|c|c|c|c|}
\hline \multirow[b]{2}{*}{ Patient } & \multirow{2}{*}{$\begin{array}{l}\text { Duration of clozapine } \\
\text { treatment (weeks) }\end{array}$} & \multirow{2}{*}{$\begin{array}{l}\text { Clozapine dose } \\
\text { (mg/day) }\end{array}$} & \multirow[b]{2}{*}{ Concurrent medication (mg/day) } & \multirow{2}{*}{$\begin{array}{l}\text { Clozapine/norclozapine } \\
\text { level (ng/mL) }\end{array}$} & \multicolumn{2}{|c|}{ CGI } & \multirow[b]{2}{*}{$\mathrm{CP}$} & \multirow[b]{2}{*}{ IB } & \multicolumn{4}{|c|}{$A D$} \\
\hline & & & & & Pre & Post & & & Low mood & Anxiety & Anger & Lability \\
\hline A & 12 & 325 & Quetiapine (200 mg tapering dose) & $350 / 140$ & 6 & 4 & $\uparrow$ & $\uparrow \uparrow$ & $\leftrightarrow$ & $\uparrow$ & $\uparrow \uparrow$ & $\uparrow$ \\
\hline B & 14 & 200 & Mirtazipine (30 mg) & $270 / 210$ & 5 & 3 & $\leftrightarrow$ & $\uparrow \uparrow$ & $\leftrightarrow$ & $\leftrightarrow$ & $\uparrow$ & $\leftrightarrow$ \\
\hline c & 12 & 175 & $\begin{array}{l}\text { Chlorpromazine }(400 \mathrm{mg}) \\
\text { Duloxetine }(30 \mathrm{mg}) \\
\text { Sodium-valproate } 1600 \mathrm{mg} \text { ) }\end{array}$ & $160 / 70$ & 5 & 3 & $\uparrow \uparrow$ & $\uparrow \uparrow$ & $\uparrow \uparrow$ & $\uparrow \uparrow$ & $\uparrow \uparrow$ & $\uparrow$ \\
\hline D & 38 & 150 & $\begin{array}{l}\text { Chlorpromazine }(125 \mathrm{mg}) \\
\text { Methadone }(30 \mathrm{mg}) \\
\text { Tropimarate }(200 \mathrm{mg}) \\
\text { Trihexyphenidyl }(6 \mathrm{mg})\end{array}$ & $230 / 110$ & 5 & 3 & $\uparrow$ & $\uparrow$ & $\uparrow \uparrow$ & $\uparrow$ & $\uparrow$ & $\uparrow \uparrow$ \\
\hline$E$ & 65 & 100 & Fluoxetine $(40 \mathrm{mg}$ ) & $150 / 60$ & 7 & 3 & $\uparrow \uparrow$ & $\uparrow \uparrow$ & $\uparrow \uparrow$ & $\uparrow \uparrow$ & $\uparrow \uparrow$ & $\uparrow \uparrow$ \\
\hline $\mathrm{F}$ & 7 & 100 & $\begin{array}{l}\text { Amisupiride }(600 \mathrm{mg}) \\
\text { Diazepam }(15 \mathrm{mg}) \\
\text { Trihexyphenidyl }(20 \mathrm{mg}) \\
\text { Venlafaxine }(300 \mathrm{mg})\end{array}$ & $N / A$ & 5 & 3 & $\uparrow$ & $\uparrow \uparrow$ & $\leftrightarrow$ & $\leftrightarrow$ & $\uparrow$ & $\uparrow$ \\
\hline G & 67 & 150 & $\begin{array}{l}\text { Sertaline }(50 \mathrm{mg}) \\
\text { Sodium valproate }(1200 \mathrm{mg}) \\
\text { Pregabalin }(300 \mathrm{mg})\end{array}$ & $170 / 80$ & 6 & 3 & $\uparrow \uparrow$ & $\uparrow \uparrow$ & $\uparrow \uparrow$ & $\uparrow \uparrow$ & $\uparrow$ & $\uparrow$ \\
\hline
\end{tabular}

\section{TABLE 3. Metabolic parameters}

\begin{tabular}{|c|c|c|c|c|c|c|c|}
\hline \multirow[b]{2}{*}{ Patient } & \multicolumn{3}{|c|}{ Pre-clozapine } & \multicolumn{4}{|c|}{ Post-clozapine } \\
\hline & BMI & $\begin{array}{l}\text { Fasting blood } \\
\text { glucose }\end{array}$ & $\begin{array}{l}\text { Total cholesterol:HDL } \\
\text { ratio }\end{array}$ & BMI & $\begin{array}{l}\text { Fasting blood } \\
\text { glucose }\end{array}$ & $\begin{array}{l}\text { Total cholesterol:HDL } \\
\text { ratio }\end{array}$ & Side effects \\
\hline$A$ & 33.9 & $\mathrm{n} / \mathrm{a}$ & $3.4: 1$ & 32.0 & 5.4 & $3.1: 1$ & Drowsy, tachycardia \\
\hline B & 29.1 & 5.0 & $8.6: 1$ & 32.2 & 5.7 & $11.9: 1$ & Hypersalivation, drowsy, slurred speech \\
\hline C & 28.4 & 5.0 & $4.6: 1$ & 31.8 & 5.0 & $\mathrm{n} / \mathrm{a}$ & Drowsy, slurred speech, hypersalivation \\
\hline D & 27.1 & 5.7 & $9.6: 1$ & 24.4 & 5.6 & $4.6: 1$ & Drowsy \\
\hline $\mathrm{E}$ & 27.5 & 4.8 & $4.0: 1$ & 31.5 & 5.6 & $5.2: 1$ & Drowsy \\
\hline $\mathrm{F}$ & 33.7 & 4.8 & $2.9: 1$ & 31.7 & 4.1 & $5.3: 1$ & Various: non-specific, drowsy \\
\hline G & 31.8 & 4.9 & $\mathrm{n} / \mathrm{a}$ & 37.4 & 4.8 & $5.5: 1$ & Drowsy, slurred speech, weight gain \\
\hline
\end{tabular}

BMI: Body Mass Index, HDL: high density lipid, n/a: information not available.

BMI was 30.2 before clozapine was initiated; this increased to 31.6 after treatment. The result was positively skewed by Patient G's significant BMI increase from 31.7 to 37.4 . There was a minor increase in fasting blood sugar results (mean 5.0 pre-clozapine and 5.2 post-clozapine). Finally, there was a slight increase in total cholesterol:HDL ratios (mean 5.5:1 pre-clozapine, 5.9:1 post-clozapine).

All patients reported a similar profile of side effects. These included drowsiness, hypersalivation, and slurred speech. One patient (Patient F) discontinued clozapine, despite "feeling better," due to various side effects and his subsequent noncompliance. None of the patients presented with neutropenia or agranulocytosis after initiation of clozapine.

\section{Patient case reports}

Patient A has a history of conduct disorder as a child, and presented in his adolescence with violent thoughts, animal abuse, and incidents of interpersonal violence. His index offence involved a serious assault on one of his parents with a knife, and he was convicted of attempted murder. He came to the hospital with symptoms of self-harm, emotional lability, and numerous acts of violence against fellow patients and staff. $\mathrm{He}$ has remained an inpatient for the last 7 years. Since 2011, he has had over 88 incidents of verbal aggression and has physically assaulted or attempted to assault fellow patients and staff on 16 accounts. Two years ago, he responded to clozapine for 8 months, but this 
TABLE 4. Change in levels of aggression 90 days before and after clozapine initiation

\begin{tabular}{|c|c|c|c|c|c|c|c|c|c|c|c|}
\hline \multirow[b]{3}{*}{ Patient } & \multicolumn{8}{|c|}{ Total number of violent incidents } & \multirow{3}{*}{$\begin{array}{l}\text { \% Reduction in total } \\
\text { number of incidents }\end{array}$} & \multirow{3}{*}{$\begin{array}{c}\text { Risk of violence to } \\
\text { others* }\end{array}$} & \multirow{3}{*}{$\begin{array}{c}\text { Dependency } \\
\text { level }\end{array}$} \\
\hline & \multicolumn{2}{|c|}{ Verbal aggression } & \multicolumn{2}{|c|}{$\begin{array}{l}\text { Aggression against } \\
\text { property }\end{array}$} & \multicolumn{2}{|c|}{$\begin{array}{c}\text { Aggression against } \\
\text { others }\end{array}$} & \multicolumn{2}{|c|}{ Self-harm } & & & \\
\hline & Pre & Post & Pre & Post & Pre & Post & Pre & Post & & & \\
\hline A & 22 & 0 & - & - & - & - & - & - & $100 \%$ & $\downarrow$ & $\leftrightarrow$ \\
\hline B & 2 & 2 & 1 & 0 & - & - & - & - & $33.3 \%$ & $\downarrow$ & $\downarrow$ \\
\hline C & - & - & - & - & - & - & - & - & - & $\downarrow$ & $\leftrightarrow$ \\
\hline D & 6 & 1 & - & - & - & - & - & - & $83.3 \%$ & $\downarrow$ & $\leftrightarrow$ \\
\hline $\mathrm{E}$ & 6 & 0 & - & - & 1 & 0 & 2 & 0 & $100 \%$ & $\downarrow$ & $\downarrow$ \\
\hline $\mathrm{F}$ & 1 & 0 & 3 & 0 & - & - & - & - & $100 \%$ & $\downarrow$ & $\leftrightarrow$ \\
\hline G & 5 & 0 & 1 & 0 & - & - & - & - & $100 \%$ & $\downarrow$ & $\downarrow$ \\
\hline
\end{tabular}

Pre: number of incidents in 90 days prior to starting clozapine; Post: number of incidents in most recent 90 days on clozapine; $\downarrow$ reduction; $\uparrow$ increase; $\leftrightarrow$ no change; and - no incidents.

*As assessed by HCR-2041 (43) and hospital risk assessment.

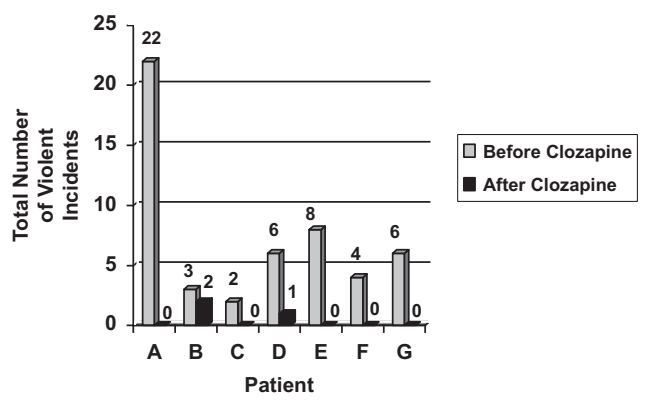

FIGURE 1. Number of violent incidents before and after clozapine treatment. Before clozapine: number of incidents in 90 days prior to starting clozapine; After clozapine: number of incidents in most recent 90 days on clozapine.

was stopped due to poor compliance. Since being re-challenged on clozapine, his incidents of aggression have completely ceased, his seclusion hours have more than halved, he is less irritable, and he engages better with staff and fellow patients.

Patient B has a significant history of violence dating back to his early childhood and has over 60 convictions, including assault, arson, criminal damage, sexual assault, attempted murder, and witness intimidation. His index offence was the murder of a fellow prisoner by strangulation and attempted decapitation. He has had several incidents since moving from prison to hospital services, including barricading a door and making serious threats of violence toward staff. Since starting clozapine, he has appeared calmer, violent incidents have reduced, there has been no self-harm, and he has engaged better with staff and other patients. In light of clinical improvement, there are now plans to move him back to prison and prepare him for release on license after he has finished serving his sentence.
Patient $\mathrm{C}$ has multiple convictions for assault, actual bodily harm, and the possession of weapons. His index offence was an extremely violent homicide where the victim was hit over the head 30-40 times with a metal bar. He frequently has violent fantasies about killing others and stabbing people with knives. Despite these intense feelings, he has managed to control his impulses while in the hospital and has had no recent incidents of outward aggression toward staff or patients. After the addition of clozapine to his treatment regime, which already included chlorpromazine, Patient $\mathrm{C}$ reported feeling better "mentally." Since starting clozapine, his internal aggression and tendency for violence has improved, and he has engaged well with dialectical behavioral therapy and occupational therapies.

Patient D has an index offence of robbery and wounding with intent to cause grievous bodily harm. He has a significant history of assault, robbery, animal cruelty, and substance misuse, and he poses a significant risk of violence to others. Before starting clozapine, the patient was stable but could be verbally abusive toward staff at times. He also refused to engage in any OT or psychological therapies. After commencing treatment on clozapine, his episodes of aggression have reduced, he is now engaging better with staff, and he has been removed from the high risk register.

Patient E has multiple convictions of rape and sexual violence, and he has displayed significant interpersonal violence toward others while in prison and hospital care. He also has a high risk of self-harm and made serious attempts to self-mutilate while in prison. Before starting clozapine, Patient E could be aggressive and had to be reminded about inappropriate behavior toward female staff. After clozapine was started, it was noted by staff that he appeared calmer. At this point, he also began to engage more frequently in OT and psychological 
treatment with great success. He has displayed few incidences of violence, engages well, and has been moved to a rehabilitation ward. There is a plan to move him to a medium security unit.

Patient $\mathrm{F}$ has numerous violent convictions, including assault, actual bodily harm, and the possession of weapons. While in the hospital, this violence has continued, and he is at high risk of aggression, assault, and fashioning weapons from sharp objects. During his short trial of clozapine, it was noted by staff that he showed improvement and was more settled. The patient stated that he "felt better," and he continued to engage well with psychological therapies. There were plans for him to be moved to a lower dependency rehabilitation ward. However, clozapine was stopped after only 7 weeks due to side effects, including drowsiness, which led to patient noncompliance. In the weeks following discontinuation of clozapine, Patient F did not show any signs of immediate relapse. However, several months later, he had to be moved to a higher dependency ward, as he had begun to destabilize. While writing this report, it was noted that patient $\mathrm{F}$ has been restarted on clozapine in the hope he will show a similar response as in his previous trial.

Patient $G$ has various convictions beginning at adolescence. His index offence was robbery with assault, which resulted in grievous bodily harm, and assaults on prison staff on numerous occasions causing serious injuries. Upon admission to the hospital, he had a history of self-harm, failure to comply with medication, and violence toward staff. His aggression toward others seemed to settle after only a few weeks on clozapine, and there was a significant reduction in the frequency of incidents reported. At this time, he has begun engaging well with activities off-ward and was moved to a lower security, rehabilitation ward. He has recently been recommended for transfer to a medium security unit.

\section{Discussion}

We report a case series of 7 forensic patients with ASPD and significant histories of violence toward others who were being treated with clozapine in a high security hospital. Among the robust socio-demographic and clinical predictors for dangerousness in people suffering with mental illnesses, previous history of violence and/or incarceration, aggression at the time of referral, and aggression at the time of hospitalization have been identified. ${ }^{46}$ These factors are present in our patients, and hence initiation of clozapine was clinically justified, keeping in perspective the additional facts that clozapine has been shown to be of benefit in certain subtypes of personality disorders, ${ }^{23,27}$ coupled with reducing aggression in schizophrenia. ${ }^{46}$
All of the patients also scored high on psychopathy as determined by PCL-SV and additionally by PCL-R (in one patient). All 7 of the patients showed clinical improvement in symptoms with the commencement of clozapine treatment and also a reduction in their risk of violence to others. Specifically, 6 of the 7 patients showed improvement in cognitive-perceptual symptoms, all showed improvement in impulsive-behavioral dyscontrol, 4 in low mood, 5 in anxiety, 7 in anger, and 6 in mood lability domains. Overall, clozapine treatment showed exceptional improvement in treating all symptom domains, with maximum benefit in the improvement of the severity of impulsive-behavioral dyscontrol and reducing anger.

Two of the patients who had a presentation of selfharming behavior showed a reduction in this risk. Six of the 7 patients displayed a reduction in the total number of violent incidents, with 4 of the 6 showing a $100 \%$ reduction. The dose of clozapine prescribed was below the therapeutic dose for schizophrenia $(350 \mathrm{ng} / \mathrm{mL})^{47}$ for 5 of the 6 patients whose levels were sampled. All patients showed an improvement in engagement with occupational, vocational, and/or psychological work. Metabolic parameters (where available) were largely unchanged, except for 1 patient who had a significant increase in BMI from 31.8 to 37.4. Considering this effect, clozapine may have caused minor weight gain in our patient sample. In some cases, there was unexpected improvement in metabolic parameters, which may be due to increased engagement in physical activities such as sports and leisure facilities. Side effects reported by the patients included drowsiness, hypersalivation, and slurred speech, which are all commonly reported sideeffects. It is relevant to mention here that patients were notified of the potential for these side-effects before commencing clozapine. In 1 patient, various side-effects led to the discontinuation of clozapine treatment after only 7 weeks. To our knowledge, this is the first report to demonstrate that clozapine treatment may have a beneficial effect on ASPD patients with high psychopathy, especially in reducing the risk of violence to others.

\section{Pharmacodynamic rationale for treatment with clozapine}

Clozapine has an extensive range of actions, and has a potent affinity for $\mathrm{D}_{1}, \mathrm{D}_{2}, \mathrm{D}_{4}, 5-\mathrm{HT}_{2 \mathrm{~A}}, 5-\mathrm{HT}_{2 \mathrm{C}}, 5-\mathrm{HT}_{3}$, muscarinic, $\alpha_{1}$-adrenergic, and histamine $\mathrm{H}_{1}$ receptors; inverse agonist activity at histamine $\mathrm{H}_{2}$ receptors. ${ }^{48}$ The full range of actions induced by clozapine is not yet fully understood. ${ }^{18,19,21,49}$ The virtue by which clozapine is particularly efficacious in treatment resistant schizophrenia, and in reducing violence, may be because of this diverse receptor profile.

Animal studies suggest that dopamine has considerable influence in mediating emotion, stress response, 
aggression, and impulsivity. ${ }^{50-52}$ Additionally several studies have demonstrated the association between abnormal dopamine metabolite (HVA) levels and impulsivity. ${ }^{53,54}$ These effects are particularly relevant to borderline and antisocial personality disorders, which are characterized by emotional dysregulation and impulsivity. ${ }^{45}$ Dopamine dysfunction has been postulated as an underlying pathology in BPD, and this is supported by evidence that personality disorder symptoms can be treated by neuromodulators that improve dopamine dysfunction, such as the atypical antipsychotic clozapine. $^{55}$

Additionally, it has been shown that serotonin (5HT) has a key role in the modulation of aggressive behavior, ${ }^{54-62}$ and several studies have identified an association between serotonin metabolite (5-HIAA) in human cerebrospinal fluid and antisocial behavior such as violence, homicide, arson, and child abuse. ${ }^{57,58,63}$ The extent to which serotoninergic dysfunction influences aggression is dependent on a complex interplay between multiple environmental factors. ${ }^{64}$

Through its complex action on both the dopaminergic and serotinergic systems, clozapine induces antiaggressive properties, ${ }^{28,65}$ which can be of benefit in the treatment of personality disorders. However, further research is needed to evaluate the pharmacodynamic basis for clozapine's efficacy in this patient group.

\section{Existing literature}

It is difficult to compare our results with the current literature due to scarcity of studies reporting on pharmacological treatment in ASPD. However, there are several studies that demonstrate the positive effect of clozapine treatment in BPD. ${ }^{23-27}$ While we report 7 patients with primary ASPD, it is notable that 5 of these patients had concurrent borderline personality traits. Hence, one may argue that the improvement in violence may be the effect of clozapine in ameliorating the borderline pathology. Antisocial personality is remarkably similar to borderline type personality, as they share the same core pathology-affective instability and impulsivity. ${ }^{66}$ It can therefore be suggested that the benefit of clozapine is not due to the treatment of comorbid borderline traits, but rather that it targets the same spectrum of symptoms that are found in both BPD and ASPD.

However, our patient subgroup is very different to the subgroups in literature that have demonstrated the effectiveness of clozapine in BPD. Our patients' primary difficulties were antisocial behavior, histories of serious violence including homicide, and levels of risk such that they necessitated high-security hospital treatment. Therefore, we suggest that the benefits of clozapine our patients displayed are not merely explained by an amelioration of their borderline pathology.

We have considered the role of concurrent medication, as 5 of the patients were on antidepressants, and 4 were on mood stabilizers. Both can improve symptom domains. However, it is to be noted that these concurrent medications predated the initiation of clozapine, and no changes in dose were made after initiation of clozapine. Also, clozapine treatment was only considered because the concurrent medication (antidepressant or mood stabilizer) in itself was ineffective.

A meta-analysis ${ }^{1}$ examined the actions of psychotropic medication on various symptom domains in severe personality disorder and found that antipsychotics rather than mood stabilizers or antidepressants (level of evidence: randomized controlled trials) led to improvement in cognitive perceptual symptoms, whereas improvement in the impulsive-behavioral dyscontrol and in the affective dysregulation domains were found to respond to either antipsychotics, antidepressants, or mood stabilizers. Therefore, the mechanism for improvement in the cognitive perceptual domain may be due to improvement in potential dopamine dysfunction, whereas, impulsive-behavior dyscontrol and affective dysregulation domains are governed in addition by potential serotonin and noradrenergic dysfunction, respectively. ${ }^{67}$ Our findings were that clozapine improved functioning in all symptom domains, which may be attributed to the diverse spectrum of receptor actions by clozapine. $^{23}$

Our patients were detained in a high-security hospital by virtue of posing the highest levels of risk of violence toward others. Importantly, there was a significant reduction in this risk as demonstrated by reduction in incidents, risk assessments, and movement of patients to lower dependency wards. While this may be due to the specific anti-aggressive property of clozapine, it may be secondary to improvement in cognitive perceptual or impulsive-behavioral dyscontrol domains.

\section{Low dose}

The patients in our study achieved clinical response with relatively low doses of clozapine (mean dose: $171 \mathrm{mg}$, range: $100-325 \mathrm{mg}$ ). Five of the 6 clozapine level samples were below the recommended therapeutic dose level for treatment of schizophrenia $(350 \mathrm{ng} / \mathrm{mL}),{ }^{47}$ and the seventh patient (for whom clozapine levels could not be done) showed clinical benefit with only $100 \mathrm{mg} /$ day of clozapine.

Our findings of low-dose treatment efficacy are similar to that of a previous study that investigated successful low-dose clozapine treatment in $\mathrm{BPD}^{25}$ and recent reviews on pharmacotherapy of $\mathrm{BPD} .{ }^{68,69}$ Hence, further research is warranted on treatment dosing and 
plasma levels of clozapine for the specific treatment of personality disorders, especially ASPD.

We consider that personality disorder treatment may require lower doses of clozapine, as the focus is on improvement in impulsivity and emotion regulation, ie, symptomatic improvement. Treatment of these symptoms may require lower doses of clozapine compared to the psychotic symptoms displayed in schizophrenia. ${ }^{68}$ In fact, in a recent review, it has been pointed out that heterogeneous presentation of BPD lends itself to a symptom-targeted approach based on available research evidence $^{69}$; this issue may operate similarly for patients with ASPD.

\section{Psychopathy}

All the patients presented with high psychopathy, with the minimum assessed PCL-SV level falling at the 83rd percentile for forensic psychiatric populations (mean: 19.7; approximately 88th percentile) ${ }^{38}$ The prevalence of psychopathy in the general population is estimated to be $1 \%$, and between $15-25 \%$ of the prison population. ${ }^{70}$ Although similar and often comorbid, ASPD and psychopathy are considered separate diagnoses. Research on prisoners found that $50-80 \%$ had ASPD, but only $20 \%$ qualified, and therefore were considered to be high psychopathy. ${ }^{71}$ High psychopathy in ASPD patients is considered to be clinically relevant because it has proven to be a valid predictor of future violence and risk of reoffending. ${ }^{72}$

There is emerging evidence that psychopathy is strongly associated with dopaminergic system abnormalities and possibly serotonin dysregulation. ${ }^{73-75}$ Neuroimaging studies support prefrontal structural and functional impairments in this offender subgroup. ${ }^{76-78}$ To date there is no literature on the effectiveness of antipsychotics in psychopathic personality disorder. Our findings support the notion that clozapine may provide clinical benefit leading to risk reduction of violence in psychopathic ASPD. We consider this an important area for future research.

\section{Concurrent Axis I diagnosis}

Our patients benefited from detailed psychiatric assessments by a range of professionals and treatment in both hospital and prison settings. This detailed evaluation process did not substantiate the presence of an Axis I disorder such as schizophrenia or schizo-affective disorder. The presentation of quasipsychotic symptoms or psychotic-like symptoms in severe personality disorder with borderline/paranoid pathology is not uncommonly encountered, ${ }^{79}$ and symptoms are known to respond to treatment with atypical antipsychotics. ${ }^{27}$ It is unlikely that our patients showed a response due to treatment of a concurrent psychotic illness, but instead benefited from the reduction in the severity of their personality disorder.

\section{Important considerations}

The retrospective nature of this case series, lack of objective rating scales, and the small sample size are some of the factors that limit our ability to draw firm conclusions from our data. The data in the medical records as available to the authors may not have been collected similarly across and within subjects. Studies conducted in a high-security hospital typically involve patients who are considered extreme cases in terms of their presentation and associated risks (and accordingly their management), and this may limit the ability of our results to be generalized and be representative of a larger population. This study also did not control for confounding variables such as other medications or psychological therapies and the therapeutic relationship between the patients and their treating team, and this may well have contributed to their improvement. All subjects reported drowsiness as a side-effect, which may have confounded behavioral outcomes; however, this may not be the case, as their increased engagement in occupational therapies indicated a genuine behavioral improvement.

However, there are also advantages to our approach. We were able to access large volumes of historical data in a longitudinal perspective for all patients, as participants were inpatients in a high-security setting with stringent and detailed recording of clinical information. Additionally, in such a setting, there are no confounding issues in the form of concurrent substance misuse or irregular/lack of adherence to medications. All patients were fully adherent to the clozapine treatment, and only 1 patient had to stop treatment due to its side effects. However, this aspect of adherence to a medication such as clozapine merits further consideration, keeping in perspective earlier research that has acknowledged and cautioned regarding the issue of ensuring compliance to oral antipsychotics (including clozapine) after discharge into the community. ${ }^{32}$

\section{Cost benefit and future recommendations}

All these patients had been transferred to high-security hospital services from medium-security hospitals or from custodial settings due to unmanageable aggression and their need for treatment. High-security hospital care is extremely expensive in comparison to these alternatives, and therefore, if proved beneficial, clozapine would be of immense cost benefit to health services. Effective treatment with clozapine in these patients would reduce the duration of high-security hospital stay and encourage progression to a medium- 
security hospital or return to prison services, thereby mitigating the overall cost of treatment.

There is a considerable lack of evidence to support pharmacological treatment in ASPD; if available, it is of low impact due to small sample sizes. ${ }^{80}$ Additionally, research exploring pharmacotherapy in forensic patients is difficult to conduct, and the subjects that are enrolled in randomized controlled trials are not representative of the most difficult-to-manage patients in security units. ${ }^{81}$ Due to the scarcity of evidence, future research is definitely indicated in the field of pharmacotherapy for patients with ASPD and psychopathy.

\section{Conclusion}

Clozapine is an atypical antipsychotic that has shown to be of benefit in reducing the risk of violence in schizophrenia. We report our experience of clozapine treatment in violent ASPD patients, with predominantly high psychopathic traits, in the setting of a high-security hospital, where we found that all patients achieved clinical benefit and had reduced risk of violence toward others. To the best our knowledge, this is the first time that clozapine has been shown to be of benefit in patients with ASPD with comorbid high psychopathy. Therefore, there is need for further research to explore the effectiveness of clozapine or other atypical antipsychotics in this subgroup of personality disorder patients.

\section{Disclosures}

The authors do not have an affiliation with or financial interest in any organization that might pose a conflict of interest.

\section{REFERENCES:}

1. Ingenhoven T, Lafay $\mathrm{P}$, Rinne $\mathrm{T}$, et al. Effectiveness of pharmacotherapy for severe personality disorders: meta-analyses of randomized controlled trials. J Clin Psychiatry. 2010; 71(1): 14-25.

2. Lieb K, Völlm B, Rücker G, et al. Pharmacotherapy for borderline personality disorder: Cochrane systematic review of randomised trials. Br J Psychiatry. 2010; 196(1): 4-12.

3. Stoffers JBA, Völlm G, Rücker A, et al. Pharmacological interventions for borderline personality disorder. Cochrane Database Syst Rev. 2010; (6): CD005653.

4. Bellino S, Paradiso E, Bogetto F. Efficacy and tolerability of quetiapine in the treatment of borderline personality disorder: a pilot study. J Clin Psychiatry. 2006; 67(7): 1042-1046.

5. Hilger E, Barnas C, Kasper S. Quetiapine in the treatment of borderline personality disorder. World J Biol Psychiatry. 2003; 4(1): 42-44.

6. Villeneuve E, Lemelin S. Open-label study of atypical neuroleptic quetiapine for treatment of borderline personality disorder: impulsivity as main target. J Clin Psychiatry. 2005; 66(10): 1298-1303.

7. Nickel M, Muehlbacher M, Nickel C, et al. Aripiprazole in the treatment of patients with borderline personality disorder: a double-blind, placebo-controlled study. Am J Psychiatry. 2006; 163(5): 833-838.
8. Bellino S, Bozzatello P, Rinaldi C, Bogetto F. Paliperidone ER in the treatment of borderline personality disorder: a pilot study of efficacy and tolerability. Depress Res Treat. 2011; 2011: 680194.

9. Grootens KP, Verkes RJ. Emerging evidence for the use of atypical antipsychotics in borderline personality disorder. Pharmacopsychiatry. 2005; 38(01): 20-23.

10. Bogenschutz MP, Nurnberg G. Olanzapine versus placebo in the treatment of borderline personality disorder. J Clin Psychiatry. 2004; 65(1): 104-109.

11. Linehan MM, McDavid JD, Brown MZ, Sayrs JH, Gallop RJ. Olanzapine plus dialectical behavior therapy for women with high irritability who meet criteria for borderline personality disorder: a double-blind, placebo-controlled pilot study. J Clin Psychiatry. 2008; 69(6): 999-1005.

12. Schulz CS, Camlin KL, Berry SA, Jesberger JA. Olanzapine safety and efficacy in patients with borderline personality disorder and comorbid dysthymia. Biol Psychiatry. 1999; 46(10): 1429-1435.

13. Zanarini MC, Frankenburg FR, Parachini EA. A preliminary, randomized trial of fluoxetine, olanzapine, and the olanzapinefluoxetine combination in women with borderline personality disorder. J Clin Psychiatry. 2004; 65(7): 903-907.

14. Zanarini MC, Frankenburg FR. Olanzapine treatment of female borderline personality disorder patients: a double-blind, placebocontrolled pilot study. J Clin Psychiatry. 2001; 62(11): 849-854.

15. Keshavan M, Shad M, Soloff P, Schooler N. Efficacy and tolerability of olanzapine in the treatment of schizotypal personality disorder. Schizophr Res. 2004; 71(1): 97-101.

16. Koenigsberg HW, Reynolds D, Goodman M, et al. Risperidone in the treatment of schizotypal personality disorder. J Clin Psychiatry. 2003; 64(6): 628-634.

17. Rocca P, Marchiaro L, Cocuzza E, Bogetto F. Treatment of borderline personality disorder with risperidone. J Clin Psychiatry. $2002 ; 63(3)$ : 241-244.

18. Vauquelin G, Bostoen S, Vanderheyden P, Seeman P. Clozapine, atypical antipsychotics, and the benefits of fast-off D2 dopamine receptor antagonism. Naunyn Schmiedebergs Arch Pharmacol. 2012; 385(4): 337-372.

19. Fakra E, Azorin J. Clozapine for the treatment of schizophrenia. Expert Opin Pharmacother. 2012; 13(3): 1923-1935.

20. Chakos M, Lieberman J, Hoffman E, Bradford D, Sheitman B. Effectiveness of second-generation antipsychotics in patients with treatment-resistant schizophrenia: a review and meta-analysis of randomized trials. Am J Psychiatry. 2001; 158(4): 518-526.

21. Kane J, Honigfeld G, Singer J, Meltzer H. Clozapine for the treatment-resistant schizophrenic: a double-blind comparison with chlorpromazine. Arch Gen Psychiatry. 1988; 45(9): 789-796.

22. Meltzer, Herbert Y. Treatment-resistant schizophrenia-the role of clozapine. Curr Med Res Opin. 1997; 14(1): 1-20.

23. Chengappa KN, Ebeling T, Kang JS, Levine J, Parepally H. Clozapine reduces severe self-mutilation and aggression in psychotic patients with borderline personality disorder. J Clin Psychiatry. 1999; 60(7): 477-484.

24. Vohra AK. Treatment of severe borderline personality disorder with clozapine. Indian J Psychiatry. 2010; 52(3): 267-269.

25. Benedetti F, Sforzini L, Colombo C, Maffei C, Smeraldi E. Low-dose clozapine in acute and continuation treatment of severe borderline personality disorder. J Clin Psychiatry. 1998; 59(3): 103-107.

26. Swinton M. Clozapine in severe borderline personality disorder. The Journal of Forensic Psychiatry. 2001; 12(3): 580-591.

27. Frankenburg FR, Zanarini MC. Clozapine treatment of borderline patients: a preliminary study. Compr Psychiatry. 1993; 34(6): 402-405.

28. Buckley P, Bartell J, Donenwirth K, et al. Violence and schizophrenia: clozapine as a specific antiaggressive agent. Bull Am Acad Psychiatry Law. 1995; 23(4): 607-611. 
29. Frogley C, Taylor D, Dickens G, Picchioni M. A systematic review of the evidence of clozapine's anti-aggressive effects. Int $J$ Neuropsychopharmacol. 2012; 15(9): 1351-1371.

30. Chengappa KNR, Vasile J, Levine J, et al. Clozapine: its impact on aggressive behaviour among patients in a state psychiatric hospital. Schizophr Res. 2002; 53(1-2): 1-6.

31. Citrome L, Volavka J, Czobor P, et al. Effects of clozapine, olanzapine, risperidone, and haloperidol on hostility among patients with schizophrenia. Psychiatr Serv. 2001; 52(11): 1510-1514.

32. Dalal B, Larkin E, Leese M, Taylor PJ. Clozapine treatment of long standing schizophrenia and serious violence: a two-year follow-up study of the first 50 patients treated with clozapine in Rampton high security hospital. Crim Behav Ment Health. 1999; 9(2): 168-178.

33. Rabinowitz J, Avnon M, Rosenberg V. Effect of clozapine on physical and verbal aggression. Schizophr Res. 1996; 22(3): 249-255.

34. Ratey JJ, Leveroni C, Kilmer D, Gutheil C. The effects of clozapine on severely aggressive psychiatric inpatients in a state hospital. J Clin Psychiatry. 1993; 54(6): 219-223.

35. Volavka J. The effects of clozapine on aggression and substance abuse in schizophrenic patients. J Clin Psychiatry. 1999; 60(Suppl 12): 43-46.

36. Krakowski MI, Czobor P, Citrome L, Bark N, Cooper TB. Atypical antipsychotic agents in the treatment of violent patients with schizophrenia and schizoaffective disorder. Arch Gen Psychiatry. 2006; 63(6): 622-629.

37. Hare RD. Manual for the Revised Psychopathy Checklist (1st ed.). 1991. Toronto, ON, Canada: Multi-Health Systems. URL for other refs: http://scholar.google.co.uk/scholar?hl=en\&q=hare + checklist $\&$ btnG $=$ \&as_sdt $=1 \% 2 \mathrm{C} 5 \&$ as_sdtp $=$

38. Hart SD, Cox DN, Hare RD. The Hare Psychopathy Checklist: Screening Version (PCL: SV). Multi-HealthSystems, Inc.; 1995. Again book ( $1^{\text {st }}$ ed). Toronto, ON, Canada.

39. Guy W. The Clinical Global Impression Scale. In: Guy W, ed. ECDEU Assessment Manual for Psychopharmacology. Rev ed. Rockville, MD: U.S. Department of Health, Education and Welfare, ADAMHA, MIMH Psychopharmacology Research Branch; 1976:218-222.

40. Frankenburg FR, Zanarini MC. Clozapine treatment of borderline patients: a preliminary study. Compr Psychiatry. 1993; 34(6): 402-405.

41. Binks CA, Fenton M, McCarthy L, et al. Psychological therapies for people with borderline personality disorder. Cochrane Database Syst Rev. 2006; (1): CD005652.

42. Soloff PH. Algorithms for pharmacological treatment of personality dimensions: symptom-specific treatments for cognitive-perceptual, affective, and impulsive-behavioural dysregulation. Bull Menninger Clin. 1997; 62(2): 195-214.

43. Webster C, Douglas K, Eaves D, Hart S. HCR-20: Assessing Risk for Violence. Version 2; 1992. Burnaby, BC, Canada: Mental Health, Law and Policy Institute, Simon Fraser University.

44. World Health Organization. The ICD-10 Classification of Mental and Behavioral Disorders: Clinical Descriptions and Diagnostic Guidelines. Geneva: World Health Organization; 1992; 50.

45. American Psychiatric Association. Diagnostic and Statistical Manual of Mental Disorders. 4th ed, text rev. Washington, DC: American Psychiatric Association; 2000.

46. Glazer GM, Dickson RA. Clozapine reduces violence and persistent aggression in schizophrenia. J Clin Psychiatry. 1998; 59(Suppl 3): 8-14.

47. Spina E, Avenoso A, Facciolà G, et al. Relationship between plasma concentrations of clozapine and norclozapine and therapeutic response in patients with schizophrenia resistant to conventional neuroleptics. Psychopharmacology (Berl). 2000; 148(1): 83-89.
48. Humbert-Claude M, Davenas E, Gbahou F, Vincent L, Arrang JM Involvement of histamine receptors in the atypical antipsychotic profile of clozapine: a reassessment in vitro and in vivo. Psychopharmacology (Berl). 2012; 220(1): 225-241.

49. Stahl SM. Psychopharmacology of Antipsychotics. London: Martin Dunitz; 1999.

50. Harrison AA, Everitt BJ, Robbins TW. Central 5-HT depletion enhances impulsive responding without affecting the accuracy of attentional performance: interactions with dopaminergic mechanisms. Psychopharmacology (Berl). 1997; 133(4): 329-342.

51. Vukhac K, Sankoorika EL, Yanyan Wang. Dopamine $\mathrm{D}_{2 \mathrm{~L}}$ receptorand age-related reduction in offensive aggression. Neuroreport. 2001; 12(5): 1035-1038.

52. Wade TR, Wit HD, Richards JB. Effects of dopaminergic drugs on delayed reward as a measure of impulsive behaviour in rats. Psychopharmacology (Berl). 2000; 150(1): 90-101.

53. Chotai J, Kullgren J, Åsberg M. CSF monoamine metabolites in relation to the diagnostic interview for borderline patients (DIB). Neuropsychobiology. 1998; 38(4): 207-212.

54. Coccaro EF, Silk KR, ed. Neurotransmitter function in personality disorders. In: Biology of Personality Disorders. Washington, DC: American Psychiatric Press; 1998: 1-25.

55. Friedel RO. Dopamine dysfunction in borderline personality disorder a hypothesis. Neuropsychopharmacology. 2004; 29(6): 1029-1039.

56. Adams DB. Brain mechanisms for offence, defence, and submission. Behav Brain Sci. 1979; 2(2): 201-213.

57. Berman ME, Tracy JI, Coccaro EF. The serotonin hypothesis of aggression revisited. Clin Psychol Rev. 1997; 17(6): 651-665.

58. Brown GL. Aggression, suicide, and serotonin: relationships of CSF amine metabolites. Am J Psychiatry. 1982; 139(6): 741-746.

59. de Boer FS, Koolhaas JM. 5-HT $1 \mathrm{~A}$ and 5-HT $1 \mathrm{~B}$ receptor agonists and aggression: a pharmacological challenge of the serotonin deficiency hypothesis. Eur J Pharmacol. 2005; 526(1-3): 125-139.

60. Gowin JL, Swann AC, Moeller FG, Lane SD. Zolmitriptan and human aggression: interaction with alcohol. Psychopharmacology (Berl). 2010; 210(4): 521-531.

61. Miczek KA, Fish EW, Joseph F, De Almeida RM. Social and neural determinants of aggressive behaviour: pharmacotherapeutic targets at serotonin, dopamine and $\gamma$-aminobutyric acid systems. Psychopharmacology (Berl). 2002; 163(3): 434-458.

62. Moss HB, Yao JK, Panzak GL. Serotonergic responsivity and behavioral dimensions in antisocial personality disorder with substance abuse. Biol Psychiatry. 1990; 28(4): 325-338.

63. Constantino JN, Morris JA, Murphy DL. CSF 5-HIAA and family history of antisocial personality disorder in newborns. Am J Psychiatry. 1997; 154(2): 1771-1773.

64. Krakowski M. Violence and serotonin: influence of impulse control, affect regulation, and social functioning. J Neuropsychiatry Clin Neurosci. 2003; 15(3): 294-305.

65. Umukoro S, Aladeokin AC, Eduviere AT. Aggressive behavior: a comprehensive review of its neurochemical mechanisms and management. Aggression and Violent Behavior. 2012; 18(2): 195-203.

66. Paris P. Antisocial and borderline personality disorders: two separate diagnoses or two aspects of the same psychopathology? Compr Psychiatry. 1997; 38(4): 237-242.

67. Bateman AW, Tyrer P. Psychological treatment for personality disorders. Advances in Psychiatric Treatment. 2004; 10(5): 378-388.

68. Bellino S, Paradiso E, Bogetto F. Efficacy and tolerability of pharmacotherapies for borderline personality disorder. CNS Drugs. 2008; 22(8): 671-692.

69. Nelson KJ, Schulz CS. Treatment advances in borderline personality disorder. Psychiatric Annals. 2012; 42(2): 59-64.

70. Dolan M. Psychopathic personality in young people. Advances in Psychiatric Treatment. 2004; 10(6): 466-473. 
71. Hare RD. Psychopathy, affect and behaviour. In: Cooke DJ, Forth AE, Hare RD, eds. Psychopathy: Theory, Research and Implications for Society. Dordrecht, the Netherlands: Springer; 1998: 105-137.

72. Salekin RT, Rogers R, Sewell KW. A review and meta-analysis of the Psychopathy Checklist and Psychopathy Checklist-Revised: predictive validity of dangerousness. Clinical Psychology: Science and Practice. 1996; 3(3): 203-215.

73. Buckholtz JW, Treadway MT, Cowan RL, et al. Mesolimbic dopamine reward system hypersensitivity in individuals with psychopathic traits. Nat Neurosci. 2010; 13(4): 419-421.

74. Dolan MC, Anderson IM. The relationship between serotonergic function and the Psychopathy Checklist: Screening Version. J Psychopharmacol. 2003; 17(2): 216-222.

75. Soderstrom H, Blennow K, Sjodin AK, Forsman A. New evidence for an association between the CSF HVA:5-HIAA ratio and psychopathic traits. J Neurol Neurosurg Psychiatry. 2003; 74(7): 918-921.

76. Barkataki I, Kumar V, Das M, Taylor P, Sharma T. Volumetric structural brain abnormalities in men with schizophrenia or antisocial personality disorder. Behav Brain Res. 2006; 169(2): 239-247.

77. Kumari V, Das M, Taylor PJ, et al. Neural and behavioural responses to threat in men with a history of serious violence and schizophrenia or antisocial personality disorder. Schizoph Res. 2009; 110(1-3): 47-58.

78. Yang Y, Raine R. Prefrontal structural and functional brain imaging findings in antisocial, violent, and psychopathic individuals: a meta-analysis. Psychiatry Res. 2009; 174(2): 81-88.

79. Chopra HD, Beatson JA. Psychotic symptoms in borderline personality disorder. Am J Psychiatry. 1986; 143(12): 1605-1607.

80. Kendal T, Pilling S, Tyrer P, et al. Guidelines: Borderline and Antisocial Personality Disorders: Summary of NICE Guidance. BMJ. 2009; 338(7689): 293-295.

81. Volavka J, Citrome L. Atypical antipsychotics in the treatment of the persistently aggressive psychotic patient: methodological concerns. Schizophr Res. 1999; 35(Suppl): S23-S33. 